\title{
THE CHANGING INCIDENCE OF CONVULSIONS IN CHILDHOOD
}

BY

\author{
ROBERT A. SHANKS, M.D., M.R.C.P., F.R.F.P.S. \\ (From the Department of Child Health, University of Glasgow, and the Royal Hospital for Sick \\ Children, Glasgow)
}

Infantile convulsions have long been an enigma and in spite of the progress of medical science there remains much that is still not clear. Infants have convulsions more often than adults or older children and for this fact various explanations have been adduced. The doctrine of peripheral irritation whereby the immaturity of the infant's nervous system was held to result in convulsions on the slightest provocation was obviously unsatisfactory and led to the acceptance of a fantastic variety of stimuli to which a particular fit might be attributed. The analogy of the rigor was also inadequate. Rigors in adults are in fact comparatively rarely encountered outside malarious areas, and in any case infants are not themselves immune from them.

Tetany or spasmophilia has long been recognized as a cause of convulsions but there has been little unanimity on the extent to which infantile convulsions must be regarded as hypocalcaemic. In parenthesis it may be mentioned that with modern methods of estimating the blood calcium, the term 'hypocalcaemia' is to be preferred to either 'tetany' or 'spasmophilia' when discussing the etiology of convulsions. The lowering of the blood calcium is the only safe criterion for the diagnosis of the convulsions of tetany: other signs are very frequently absent.

Although Thiemich (1906), Husler $(1920,1921)$, and Zappert (1932) all recognized spasmophilia, which was quite distinct from epilepsy, as a cause of convulsions in infancy and early childhood, they also recognized a benign, non-recurrent 'casual' convulsion, first postulated by Hochsinger (1904) which was considered to be distinct both from tetany and epilepsy. Gebhardt (1914), however, considered most of these latter convulsions to be in fact spasmophilic. Husler and Spatz (1924) investigated the convulsions of whooping-cough and concluded that they were only very rarely spasmophilic in spite of the frequent association of rickets. Powers (1925) using the recently described micromethods for the estimation of blood cakcium, found on the other hand that most of the convulsions of whooping-cough were hypocalcaemic. The position was further complicated by the suggestion that tetany and epilepsy could not be separated so clearly and that the sequelae of recurrence and mental degeneration could follow upon tetany also (Collier, 1928; Kennedy, 1931; and Voigt, 1942).

Graham $(1932,1933)$ discussing convulsions in the first two years of life, showed that in Glasgow the commonest cause was hypocalcaemia. He had been

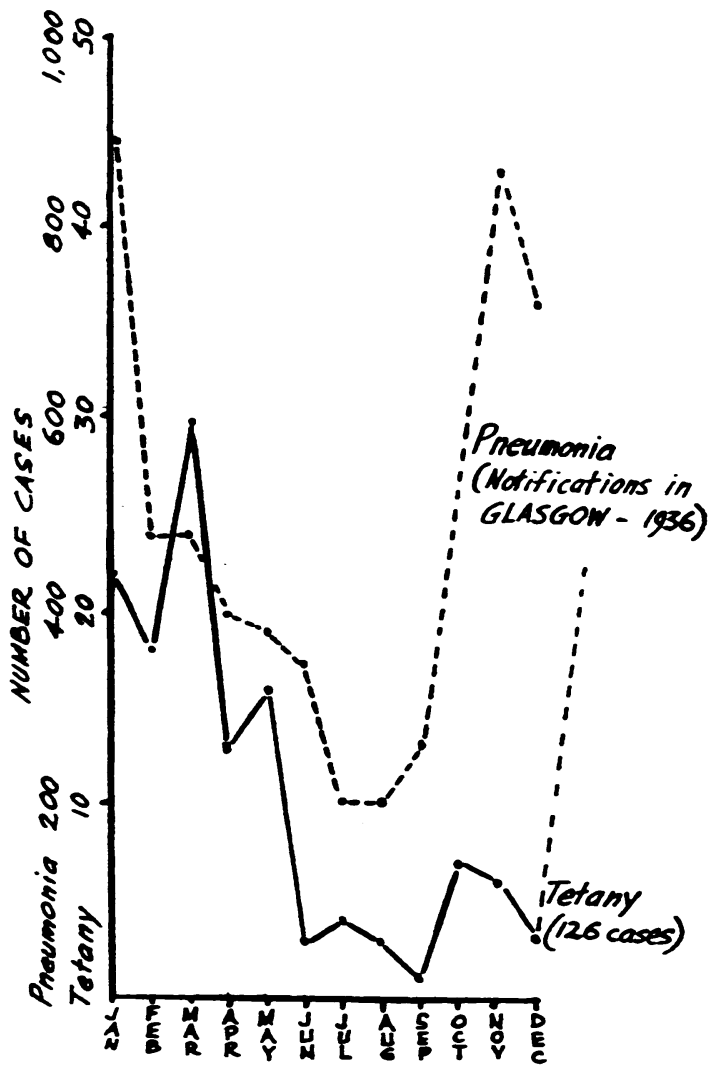

Fig. 1.-Seasonal incidence of tetany and of acute primary pneumonia.

struck by the number of children who had a convulsion at the onset of an acute infection and had also a demonstrable hypocalcaemia. If his views were correct then it would be reasonable to suppose that 
these convulsions would show the same seasonal incidence as tetany. They would appear particularly in late winter with a peak incidence in the spring. On analysis of his cases this was found to be so, whereas a control series of convulsions associated with obvious intracranial disease showed no such seasonal variation. It was, therefore, unnecessary to postulate etiological factors other than hypocalcaemia, intracranial disease, and mental deficiency to explain infantile convulsions; epilepsy in the usually accepted sense of the term is not a diagnosis to be made at this age. In Sweden, Herlitz (1941) challenged these views in favour of a specific ' initial-fever convulsion' distinct both from epilepsy and tetany. He particularly objected to the conclusion that the seasonal variation demonstrated by Graham was due to hypocalcaemia; he believed that it was no more than the seasonal variation of the associated diseases which were, in his cases, mainly acute infections of the respiratory tract. This argument seems to me to contain a false premiss. The seasonal incidence of acute respiratory infections in no way resembles that of tetany. If we take, for example, the notifications of acute primary pneumonia in Glasgow in 1936 and compare the curve (fig. 1) with that of tetany it will be seen that there is a pronounced time lag between the two curves and in particular the maximum for tetany occurs two months after that of pneumonia. Tetany gives a sharp peak in the spring (Thiemich, 1906, and Horstmann and Petersen, 1946) whereas pneumonia is obviously a disease of winter. It seems reasonable to suppose that the seasonal variation of other acute respiratory infections will follow that of pneumonia. In Ireland, Frazer (1944) sided with Graham in attributing to most infantile convulsions a rachitic basis. On the other hand Capper (1946) in America categorically denied that spasmophilia was anything but a rare cause of convulsions.

When discussing the incidence of rickets or tetany, locality and time are important and the divergence of opinion on the position of tetany as an etiological factor in infantile convulsions is most probably attributable in part at least to the different localities and periods studied. It is certain, for example, that Glasgow in the past saw very much more rickets and tetany than other cities with less poverty and over-crowding and more sunshine. Moreover, it is likely that Glasgow shared her unenviable reputation with Ireland rather than with Sweden.

It is common knowledge that there has been a marked fall in the incidence of rickets and tetany in the last decade or so and hypocalcaemia cannot to-day be regarded as a likely cause of infantile convulsions. It therefore seemed profitable to re-investigate the incidence of convulsions in order to confirm the seasonal variation of the past and determine any subsequent change. It was decided to investigate the incidence of convulsions for three representative quinquennia in the quarter century $1922-46$.

\section{Investigation}

The periods chosen were 1922-26, 1932-36, and 1942-46. Records were available at the Royal Hospital for Sick Children, and the case-sheets of medical admissions were carefully scrutinized. All cases admitted with a history. of convulsions or who developed one or more convulsions during the period of stay in hospital, were extracted. For the first period, when the medical wards of the hospital were undivided, all medical admissions were included; for the other two those of one medical unit only were taken. As the number of medical beds in the earlier period was less than in the later ones, there is no very great disparity. The total medical

TABLE 1

SEASONAL INCIDENCE OF CONVULSIONS IN CHILDREN UNDER THREE YEARS OF AGE NOT ASSOCIATED WITH PRIMARY DISEASE OF THE CENTRAL NERVOUS SYSTEM

\begin{tabular}{|c|c|c|c|c|c|c|c|}
\hline & & \multicolumn{2}{|c|}{$1942-46$} & \multicolumn{2}{|c|}{$1932-36$} & \multicolumn{2}{|c|}{$1922-26$} \\
\hline & & $\begin{array}{l}\text { Actual } \\
\text { figures }\end{array}$ & $\begin{array}{c}\text { Monthly } \\
\text { admissions }(\%)\end{array}$ & $\begin{array}{l}\text { Actual } \\
\text { figures }\end{array}$ & $\begin{array}{c}\text { Monthly } \\
\text { admissions (\%) }\end{array}$ & $\begin{array}{l}\text { Actual } \\
\text { figures }\end{array}$ & $\begin{array}{l}\text { Monthly } \\
\text { admissions }(\%)\end{array}$ \\
\hline $\begin{array}{l}\text { Jan. } \\
\text { Feb. } \\
\text { March } \\
\text { April } \\
\text { May } \\
\text { June } \\
\text { July } \\
\text { August } \\
\text { Sept. } \\
\text { Oct. } \\
\text { Nov. } \\
\text { Dec. }\end{array}$ & $\begin{array}{l}\ldots \\
\cdots \\
\ldots \\
\ldots \\
\ldots \\
\cdots \\
\cdots \\
\cdots \\
\cdots \\
\cdots\end{array}$ & $\begin{array}{l}15 \\
16 \\
20 \\
17 \\
16 \\
15 \\
12 \\
18 \\
20 \\
12 \\
14 \\
17\end{array}$ & $\begin{array}{l}2 \cdot 8 \\
4 \cdot 6 \\
4 \cdot 7 \\
4 \cdot 4 \\
3 \cdot 9 \\
4 \cdot 5 \\
3 \cdot 1 \\
3 \cdot 9 \\
4 \cdot 5 \\
3 \cdot 1 \\
3 \cdot 5 \\
4 \cdot 8\end{array}$ & $\begin{array}{l}19 \\
16 \\
28 \\
21 \\
23 \\
13 \\
12 \\
16 \\
15 \\
14 \\
12 \\
14\end{array}$ & $\begin{array}{l}6 \cdot 4 \\
5 \cdot 4 \\
8 \cdot 1 \\
6 \cdot 8 \\
6 \cdot 9 \\
4 \cdot 4 \\
4 \cdot 4 \\
4 \cdot 9 \\
4 \cdot 6 \\
4 \cdot 0 \\
3 \cdot 8 \\
4 \cdot 6\end{array}$ & $\begin{array}{r}29 \\
25 \\
24 \\
18 \\
21 \\
21 \\
5 \\
14 \\
15 \\
17 \\
16 \\
12\end{array}$ & $\begin{array}{l}5 \cdot 1 \\
5 \cdot 4 \\
5 \cdot 4 \\
4 \cdot 1 \\
4 \cdot 2 \\
4 \cdot 8 \\
1 \cdot 2 \\
2 \cdot 8 \\
2 \cdot 8 \\
3 \cdot 2 \\
3 \cdot 6 \\
2 \cdot 8\end{array}$ \\
\hline Total & $\ldots$ & 192 & 3.9 & 203 & $5 \cdot 4$ & 217 & $3 \cdot 8$ \\
\hline
\end{tabular}


admissions for the three periods under consideration were $5,706,3,769$, and 4,884 .

For the purposes of the present paper only those cases not obviously associated with intracranial disease are included; we may also, as we are concerned only with infantile tetany, restrict our consideration to those under the age of three years. It is only necessary for our purpose to record the seasonal and age incidence of these cases, but it is worthy of mention that the striking fall in the number of cases with clinical evidence of rickets and tetany abundantly confirmed our clinical impression of the virtual disappearance of these conditions. Moreover, it is interesting to note that this fall became evident in the middle period before the war-time free issue of vitamin supplements and the fortification of dried milk with calciferol.
The statistical significance of these results is discussed in an appendix to this paper. It is interesting to note that 1932-36 shows a rather smaller seasonal variation than 1922-26 and that this is in conformity with the observations upon the fall in the incidence of rickets and tetany where it was found that a slow fall was already apparent in the thirties leading to an almost complete disappearance in the forties.

During the three periods there have been 126 cases of unequivocal tetany and the seasonal variation of these may be taken as typical. On comparison of this curve (fig. 1) with those of 1922-26 and 1932-36 the similarity is obvious. (In 1922-26 the curve for the actual figures does not show a peak in March: this is because the admissions in January, 1922-26, were unusually high. Otherwise the monthly
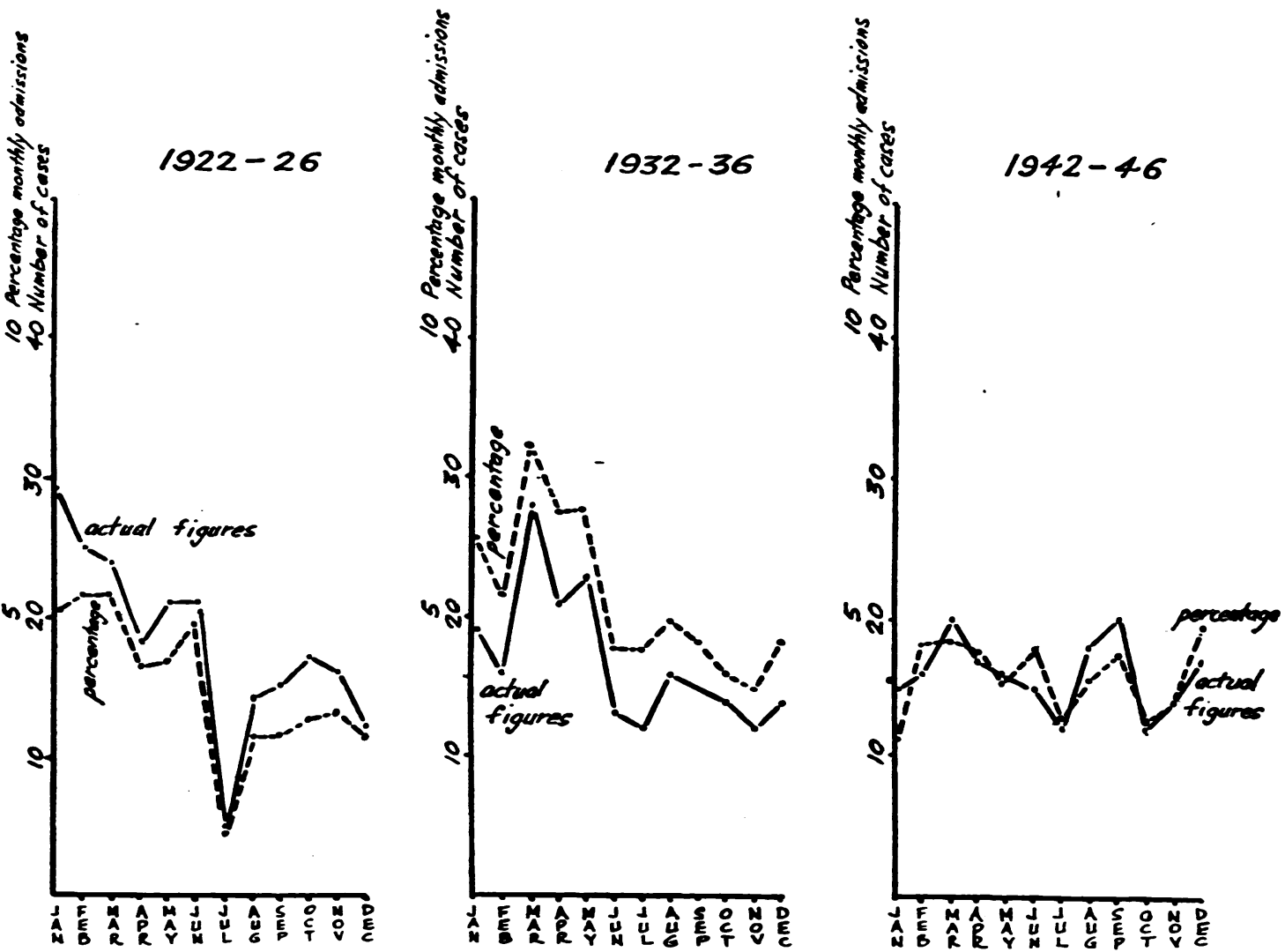

Fig. 2.-Monthly incidence of cases of convulsions under the age of three years, not associated with primary disease of the central nervous system.

Seasomal incidence. Table 1 shows the monthly incidence of these cases but they are better demonstrated graphically (fig. 2). The most striking feature of the three curves is the difference between that of 1942-46 and those for 1922-26 and 1932-36. The earlier curves fully confirm the seasonal incidence and the last shows its virtual disappearance. variation of total admissions has little effect on the seasonal variation as shown by the actual figures.)

Age incidence. The age incidence shows a similar alteration in pattern. It is only necessary to compare the findings of 1922-26 with those of 1942-46 (fig. 3) to demonstrate the striking fall in 
the tetany age-group of six to eighteen months. There has always been a numerical preponderance in the first six months of life but formerly the tetany age-group was prominently represented. Again the middle period shows a position intermediate between

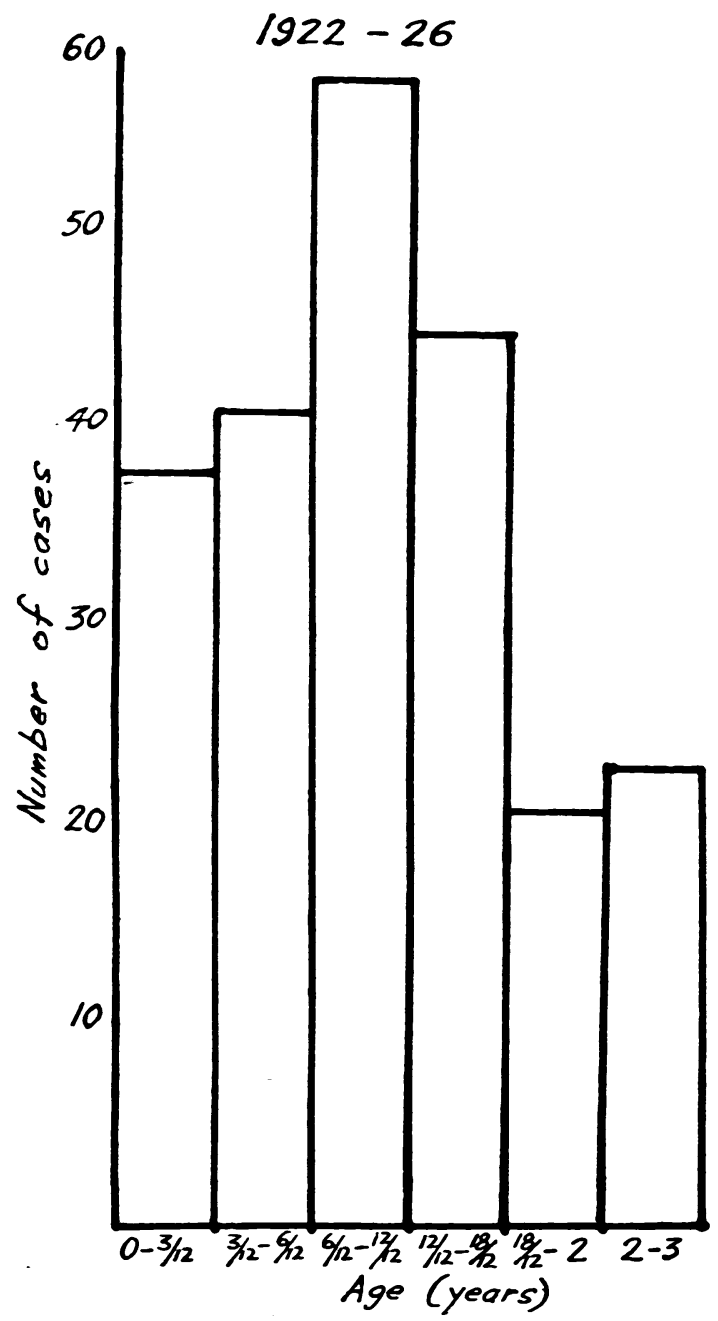

however, much the same distribution. Thiemich's (1906) curve is substantially the same. There seems to be no reasonable doubt that the curve of incidence of convulsions during the two periods 1922-26 and $1932-36$ is due to an associated hypocalcaemia.

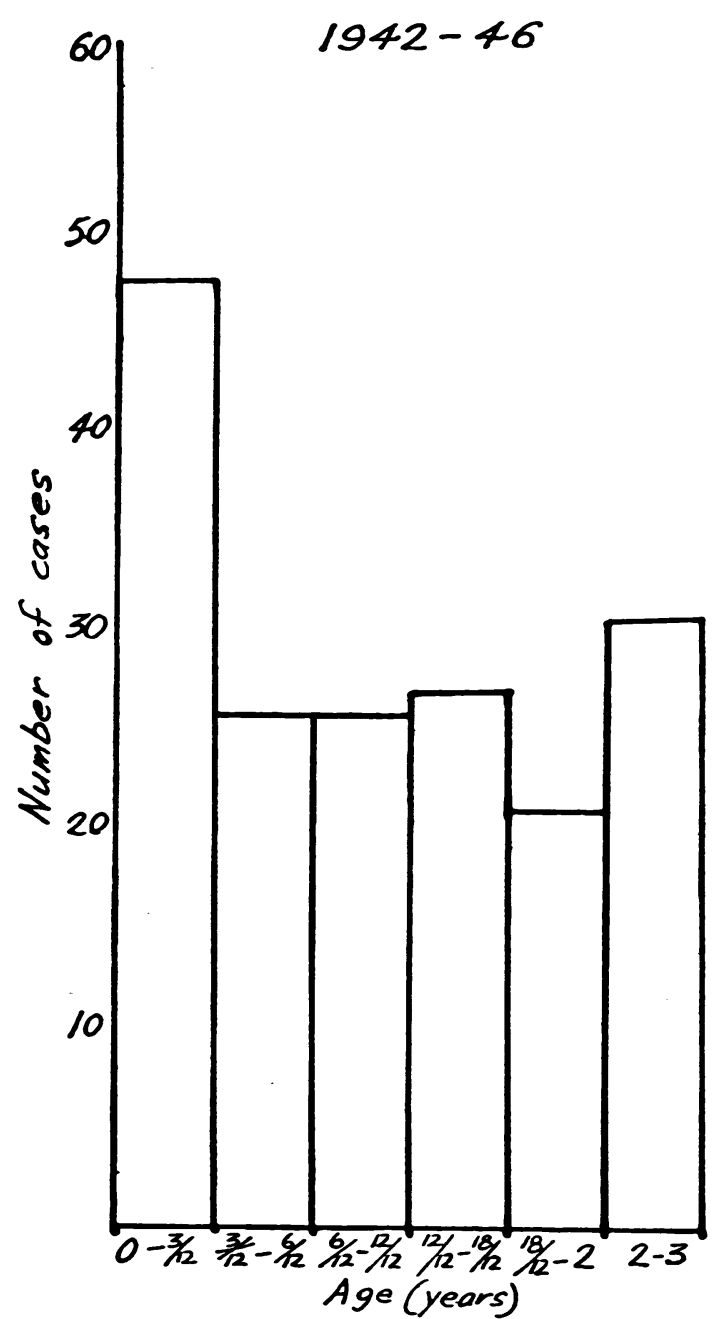

Fig. 3.-Age incidence of cases with convulsions under the age of three years not associated with primary disease of the central nervous system.

the two others. To-day the first three months are by far the most frequent age for the convulsions of infancy to appear. The 'teething' convulsions, therefore, have disappeared with the disappearance of tetany.

\section{Discussion}

The seasonal incidence of tetany is quite characteristic. Horstmann and Petersen (1946) make the point that the curve for tetany differs from that for rickets. In tetany there is a sharp peak in March whereas that for rickets is a rounder curve with,
The peak in March and the trough in the summer and autumn is typical, and, moreover, it is very difficult to suggest why this seasonal variation should have disappeared if it is not due to the disappearance of tetany. This disappearance of the seasonal variation suggests that it is concerned with some factor that has radically changed in the last quarter-century. There has been no change in the actual incidence of respiratory infections whatever improvements there may have been in the therapeutics of these diseases. The notifications, for 
example, of acute primary pneumonia in Glasgow have shown no significant fall since 1922 (M.O.H. Reports, 1922-1946).

We can hardly escape the conclusion, therefore, that there has been a striking alteration in the pattern of incidence of infantile convulsions in the last twenty-five years and that this has every appearance of being due to the virtual disappearance of hypocalcaemia as an etiological factor. That this was not so in other parts of the world is not only possible but likely. - In the past the incidence of rickets in Glasgow was unusually high.

There is a corollary arising out of these observations that opens a wider field of speculation. We have seen that there has been a considerable fall in what has been the main etiological factor in the convulsions of infancy and childhood. Normally one would expect there to be a corresponding fall in the total incidence but this is not in fact the case.

Table 2 summarizes the general incidence of all cases of convulsions admitted during the three periods under consideration. The fluctuation of the total admissions with convulsions is not helpful but if they are expressed as a percentage of the total medical admissions a comparison is permissible. It becomes apparent that the number of cases with convulsions expressed in this way is the same for $1922-26$ as it is for $1942-46$. Not only are the totals unchanged but the relative numbers apportioned between primary disease of the central nervous system and the others has also remained the same. Table 1 shows a similar position.

General incidence of convulsions. How far it is justifiable to draw general conclusions on incidence from the numbers of admissions to hospital is, of course, problematical. In this instance, however, the figures are strongly suggestive; especially as it is possible to argue that these figures indicate that

TABLE 2

GENERAL INCIDENCE OF CONVULSIONS

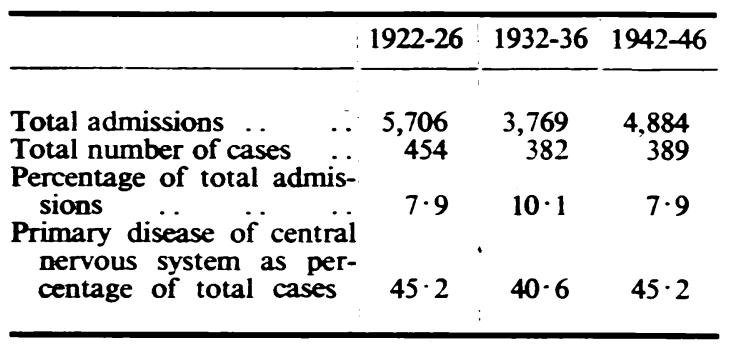

not only has there been no fall in the incidence of convulsions but that there has actually been an increase. The figures for the last two periods represent only the admissions to one medical unit. The total figures will therefore be about double this. It could be argued that there will be a tendency to admit an acute emergency such as a convulsion no matter what may be the state of the beds and that an increase in accommodation will result in a disproportionate increase in relatively minor cases. From this it would follow that the absolute increase in the number of admissions with convulsions would indicate an absolute increase in the incidence in spite of a relatively constant proportional incidence. However that may be, there has manifestly been no decrease in the incidence and this accords well with the findings in other parts of the world.

\section{Summary and Conclusions}

The seasonal and age incidence of convulsions in children under three years of age have been investigated for three five-year periods, 1922-26, 1932-36, and 1942-46.

The results demonstrate the characteristic curves of tetany in the first two periods with their virtual disappearance in the last.

From this it is concluded that in Glasgow hypocalcaemia was the predominant etiological factor in convulsions in the earlier periods under investigation but is so no longer.

The total and relative incidence of convulsions in infancy and childhood has not been reduced by this fall in the incidence of hypocalcaemia.

This investigation is in many ways a continuation of the work on convulsions by Professor Stanley G. Graham to whom I am grateful for suggesting the topic and also for ever present encouragement and unstinted advice. Dr. Robb's contribution is greater than the modest dimensions of his comment would suggest. I should also like to thank Dr. D. Campbell Suttie and his staff for access to records.

\section{REFERENCES}

Capper, A. (1946). Penn. med. J., 49, 421.

Collier, J. (1928). Lancet, 1, 587.

Frazer, M. J. L. (1944). Med. Pr., 211, 141.

Gebhardt, H. (1914). Mschr. Kinderheilk., 13, 265.

Graham, S. (1932). Glas. med. J., 117, 113.

- (1933). Acta Paediatr., 16, 572.

Herlitz, C. W. (1941). Acta Paediatr. (Suppl. 1), 29, 1.

Hochsinger, K. (1904). Dtsch. Klinik, VII, 479.

Horstmann, P., and Petersen, P. (1946). Acta. Paediatr., 33, 203.

Husler, J. (1920). Z. Kinderheilk., 26, 239.

- (1921). Ergebn. inn. Med., 19, 624.

- , and Spatz, H. (1924). Z. Kinderheilk., 38, 428.

Kennedy, F. (1931). ' On the Nature of Fits.' Association for Research in Nervous Disease. Vol. VII. Baltimore.

Medical Officer of Health Reports (1922-1946), City of Glasgow.

Powers, G. F. (1925). Amer. J. Dis. Child., 30, 633.

Thiemich, M. (1906). 'Kinderkrämpfe,' Handbuch der Kinderheilkunde. Ed. by Pfaundler, M. von, and Schlossmann, A. Vol. II. Leipzig.

Voigt, R. (1942). Mschr. Kinderheilk., 90, 294.

Zappert, J. (1932). Ergebn. inn. Med., 43, 149. 


\section{STATISTICAL NOTE ON THE SEASONAL VARIATIONS OF TABLE I}

By R. A. ROBB, M.A., D.Sc. (Department of Mathematics, University of Glasgow)

Table 1 gives the actual number of cases of convulsions in three five-yearly periods, 1922-26, 1932-36, and 1942-46. These numbers will not show the true seasonal effect owing to the fact that the number of days in each month is unequal. Over the five-year period 1922-26, for example, there are 165 days in January in which cases of convulsions can be admitted to hospital, but only 141 days for February, allowing one extra day for a leap year. The data of table 1 have, therefore, to be adjusted,

TABue la

ACTUAL INCIDENCE OF CONVULSIONS

\begin{tabular}{cc|c|c|c}
\hline & & $1922-26$ & $1932-36$ & $1942-46$ \\
\hline Jan. .. &. & 29 & 19 & 15 \\
Feb. &. & 29 & 19 & 19 \\
March &. & 24 & 28 & 20 \\
April &. & 20 & 23 & 19 \\
May &. & 21 & 23 & 16 \\
June &. & 23 & 14 & 16 \\
July.. &. & 5 & 12 & 12 \\
Aug. &. & 14 & 16 & 18 \\
Sept. &. & 16 & 16 & 22 \\
Oct. &. & 17 & 14 & 12 \\
Nov. &. & 18 & 13 & 15 \\
Dec. &. & 12 & 14 & 17 \\
\hline Total &.. & 228 & 211 & 201 \\
\hline
\end{tabular}

and this has been done on the basis of 165 days for each of the calendar months. Table la gives the adjusted data.

The probability or chance of incidence of convulsions in any one month is very small, and the counts in any one month can be considered as distributed in the Poisson fashion. To test the hypothesis that in any five-year period the number of cases of convulsions in any one month is the same except for random or accidental variations, the Poisson index of dispersion, $x^{2}$, may be used. If $x^{2}>19.7$ we may say on the 5 per cent. level of significance that the hypothesis should be rejected: that is, a significant seasonal variation exists. The following results were obtained:

\begin{tabular}{|c|c|c|}
\hline Period & $x^{2}$ & Remarks \\
\hline $\begin{array}{ll}1922-26 & \ldots \\
1932-36 & \cdots \\
1942-46 & \ldots\end{array}$ & $\begin{array}{r}28 \cdot 1 \\
14 \cdot 8 \\
5 \cdot 8\end{array}$ & $\begin{array}{l}\text { Highly significant } \\
\text { Rather below significance } \\
\text { Not significant }\end{array}$ \\
\hline
\end{tabular}

Thus there is a significant seasonal variation in 1922-26 and a tendency to such during 1932-36. The figures for 1942-46 show, however, that if a seasonal variation exists it is obscured by the accidental variations. 